\title{
Syntactic Simplicity in Dyslexic Children's Utterances
}

\author{
Mulyono \\ Departement of Indonesian Language and Literature \\ State University of Surabaya \\ Surabaya, Indonesia \\ mulyono@unesa.ac.id
}

\author{
Ketut Artawa \\ Departement of English Literature \\ Udayana University \\ Bali, Indonesia \\ artawa56@yahoo.com
}

\author{
Prima Vidya Asteria \\ Departement of Indonesian Language and Literature \\ State University of Surabaya \\ Surabaya, Indonesia \\ primaasteria@unesa.ac.id
}

\begin{abstract}
As kids suffering from language deficits, dyslexic children have unique linguistic characterisitics. This research aims to examine syntactic simplicity in dyslexic children's utterances. The data was collected through observation, audio taping, and elicitation whereas a minimalist theory was employed to analyze the syntactic simplicity and to formulate its principles. The research findings suggest that children with dyslexia tend to produce short sentences, and ellipsis, as well as demonstrate inaccurate use of 'kata tugas' (preposition, conjunction, interjection, relative pronouns) and word order. In some cases, certain syntactic structures commonly used by normal children of the same age were not found in dyslexic children's utterances. This indicates that dyslexic childen have yet to acquire all syntactic structures, particularly complex ones. The syntactic simplicity in dyslexic children's utterances can be observed from the use of verbs. As a core constituent of a sentence, verbs seem to have been perceived and used differently by children with dyslexia. The verb 'mandi' for example, is perceived as simpler than the verb 'membuat' so that it is more easily understood and appropriately used in a sentence. Similarly, the verb 'membuatkan' is perceived as more complicated than 'membuat' with the result that the former is often used inaccurately in a sentence.
\end{abstract}

Keywords—simplicity, syntactic structures, dyslexia

\section{INTRODUCTION}

Language mastered by the children consists of four aspects of language skills: listening, speaking, reading, and writing. The four aspects of language are mastered by the child gradually in accordance with the development patterns of each child. However, sometimes there are children who do not control overall, as experienced by dyslexic children. Dyslexic children (DC) are children who have difficulty in learning to read despite having an average level of intelligence or even

above average, getting enough education, and have no sensory disabilities [1].
From a neurological point of view, dyslexic children are children with brain disorders in the primary cortex of the language processor. Reading and writing disorders derived from neurological factors [2]. This can be caused by genetic factors or due to injury to the part of the brain that controls the way to read and write [3] and is characterized by difficulty in accuracy and fluency in recognizing written words, and describing and spell those words [4]

The research result about the percentage of dyslexic children showed that $17.5 \%$ of children have experienced delays in the accuracy of reading the various numbers [5]. However, another study conducted by Iglesias [6] stated that these results decreased by approximately $5 \%$, especially in males (2000). Meanwhile, Reggiani [7] mentions dyslexia occurs in $10-14 \%$ of the total population of children. Thus, it is precisely the conclusion of Yilmaz's research [8] that states there are still many students at the elementary school level who have difficulty reading or dyslexia (2008).

Somad [9] also states that dyslexic children are found in regular schools, especially in grades 1, 2, and 3. However, the actual number is not yet certain. Their number is estimated to be between $2 \%$ and $10 \%$ of the population. Some teachers assume dyslexic children as children who experience learning delays, low achievers, lazy, lack of concentration, or naughty. This assumption arises because the teacher lacks understanding of the characteristic and handling of dyslexic children so that the efforts made by the teacher have not been fully in accordance with the needs and the ability of the child. Dyslexic children need different learning programs taking into account their abilities and weaknesses [10].

Furthermore, the difficulties experienced by dyslexic children not only in reading, but also in spelling, writing, producing speech, and understanding / interpreting speech. They have difficulty in learning the components of words and sentences, experiencing delays in language development, and are almost always problematic in studying representational systems pertaining to time, direction, and mass [11]. They 
experience difficulties ranging from the field of phonology, morphology, to syntax [7]. Based on the explanation above, the focus of the problem to be studied in this research is how is the simplicity of Indonesian sentence structure that appears in the speech of dyslexic children?

\section{RESEARCH METHOD}

This research is designed in the form of descriptivequalitative research. The used approach is the approach of phenomenology [12] With this approach, the researcher assumes that the simplicity of Indonesian sentence structure in $\mathrm{DC}$ speech is a phenomenon that can be comprehensively studied.

The source of this research data is dyslexic children who use Indonesian Language as the first language. The number of research objects is five children. They are on therapy and private lessons learn to read and write. Their age range is between 8 and 10 years. This age determination is based on the Critical Age Hypothesis according to Lenneberg [13].

To obtain the data, the researcher uses two kinds of methods, namely (1) the observe method and (2) the converse method. Both methods are intended to complement each other and support each other. The observe method performed by listening to the use of language, in this case listen to the speech of children dyslexia. To complete the obtained data through this method, the researcher use the converse method with fishing technique. This technique is implemented when the subject of research is reluctant to speak because in general they are quiet type of children so that words are spoken very little. Researchers try to approach the subject by giving some questions about the things he likes or by telling stories. This technique is applied with game media, images, and a specific list of inquiries as an effort to perform deep data elicitation.

The collected data were analyzed and presented qualitatively. The process of data analysis is done by arranging the sequence of data, organizing it into a certain pattern, category, and a specific of basic description unit. In order to be in line with the sequence of predetermined problems, the data analysis in this study is organized by stages (1) identification of data, (2) data selection, (3) data encoding, (4) data classification, and (5) data analyzing. In the data analysis phase, several analytical techniques are applied, namely (a) deletion, (b) substitution, (c) change of shape (paraphrase), (d) expansion, and (e) permutation. Various methods and techniques of analysis are attempted to produce a comprehensive overview, explanation, and findings about the object under study.

\section{DISCUSSION}

As a unit of syntax, speech produced by DC have some structural variation. The structure of clauses and sentences are two units of syntax that equal. Both are minimal syntactic units possess constituent predication, either verbal or nonverbal predicate. The difference lies in intonation and punctuation. Hierarchically, clauses are part of sentence construction. The clause is a constituent component of sentence construction and can only be recognized when it is in a sentence. Sentences can be formed by one, two, or more clauses, so that there is some kind of sentences which contain different clauses.

Simple sentence consists of one clause, while the complex sentence (both coordinative and subordinative), consisting of two or more clauses[14]. Thus, the term clause which has the same reference to the term sentence are limited only for simple sentences, namely a sentence consisting of one clause.

In general, the sentences in the speech DC has a gradation of simplicity. The simplicity degrees will appear and can be analyzed by looking at the type of verb-fill function predicate sentence and the sentence structure (complete sentences and incomplete sentences). Here is the explanation of each degree of simplicity for speech of DC.

\section{A. Simplicity of Sentences Based on Type of Predicate Filler Verbs}

According to the Generative Theory [15], the phrase developed by the phrase structure with merger and movement operations. With merger syntactic operations, two categories combine to form a sequence of higher category. How is the process? Simply put as follows: lexical item (eg, verb) selected from the lexicon later joined by another item is selected to form a sequence of higher category that is as verbal phrase (VP). In this process the verb has a very important role because it becomes the central element of the sentence. The verb has an argument structure, i.e. the role of the participant inherent in the verb and both the verb and its argument must be expressed in the syntax for the grammatical sentence. The argument structure of each verb also needs to be encoded in the lexicon by the verb itself considering that each verb demands a different number of arguments. For example, consider the following few sentences:

(1) Adik mandi.

\section{'Sister shower'}

(2) Adik minum susu.

\section{'Sister drink milk'}

(3) Mama membuatkan adik susu.

\section{'Mama make sister's milk'}

The important difference between the three sentences is first, the number of arguments from the three sentences is different so the syntactic structure is also different. This difference in syntactic structure has important implications in the process of understanding and producing sentences for the DC.

Sentence (1) has a simpler structure, only two constituents just as verbs "mandi" only requires "adik" (ie someone who is doing the bath activity). Sentence (2) is composed of three constituent for "minum" verbs require a "adik" (someone who do the drink activity) and "susu" (something that drink). As for the sentence (3) consists of four constituent because "membuatkan" verbs require "mama" (someone who conduct activities) and "adik" (someone who become "peruntung" of activity) and "susu" (something that to be make). In addition, every argument of the verb also has a semantic role, namely as 
Agent, Patient, Theme, Fortune, or Purpose. "Mandi" requires only one argument, and therefore, is called the one-verb argument. "Minum" requires two arguments, and is therefore referred to as a two-argument verb. Likewise, the verb "membuatkan" requires three arguments, and therefore referred to as a three-argument verb. The fewer the number of arguments required by the core predicate verb of the sentence, the more simple the structure of the sentence for DC. That's the rational explanation why the sentence (1) is more simple (easy to understand) than the sentence (2) for DC. Instead, the sentence (3) more complex (elusive) than the sentence (2).

\section{B. Simplicity of Sentences Based on Structure Patterns}

\section{1) Simple Sentence}

Sentences spoken by DC mostly simple sentences (basic sentences), namely sentence that each function is filled by the core phrase. Such as these have the characteristics: (1) only one verb; (2) does not contain elements connected by conjunction with other elements; (3) the subject, object, and the predicate of the simple sentence has a minimum specification; and (4) does not contain a secondary carrier, such as negation, orders, inquiries, and modalities. Simple sentence consists of one clause implies that there is only one pattern in the basic sentence, which is simple structure. Because it only has one pattern and a simple structure, so that it is easy to be understand and produced by DC.

Generally simple sentence manufactured by DC can be broken up into two, namely simple sentence with predicate verbs and nonverba filled. Here are some examples.

(4) Ica menangis.

$$
\text { 'Ica cry' }
$$

(5) Aku punya hape.

\section{'I have hp'}

On the data (4) and (5) above, the simple sentence constituents formed by the NP as the subject function filler "Ica" and " $A k u$ " then followed by a constituent VP filler predicate function which includes "menangis" and "punya hape". Sentences with predicate functions filled by verbs or verbal phrases like this are commonly referred to as verbal sentences. Based on the type of the verb, the sentence that appears in the speech DC can be classified into three types, namely "intransitif" sentence, "ekatransitif" sentences, and sentences "dwitransitif" [14]

Based on frequency of application, the existence of the "ekatransitif" sentence in the speech DC quite high. From the 270 complete sentences of the collected data, there are 49 (= $18.14 \%$ ) "ekatransitif" sentence. Some examples can be seen in the data below.

(6) Kakek makan bubur.

'Grandfather ate porridge'

(7) Opahku menyembuhkan orang.

'My opah heals people'
Predicate verb in the sentence above each was "makan" at (6) and "menyembuhkan" at (7). As a predicate transitive verb above each have two core argument, which is "kakek" as Ag (eating) and "bubur" as Ps (eaten) in sentence (6); "opahku" as Ag (who healed me) and "orang" as Ps (which is cured) at sentence (7).

Another thing that quite interesting to discuss in this section is so many phenomena transitive verb usage in speech DC. Only, transitive verbs do not necessarily form a transitive sentence. This is because the transitive verb is not followed by the OBJ core argument that should be accompanying it. Sentences with predicate transitive verbs not accompanied by OBJ core arguments are grouped into "intransitif" sentences [14]

Interesting phenomena to note that associated with "dwitransitif" sentence is not found in this type of sentence in the speech DC. The sentence stating the meaning of 'for the others' (benefactive), expressed in the form of sentences "ekatransitif" with destination information, such as data (6) and (7) below.

(8) Ibu membuat bubur untuk adik.

'Mother makes sister's porridge'

(9) Aku membawa kue buat bu guru.

'I brought a cake for my teacher'

This is suspected to be closely related to the development of cognition in DC. In accordance with Peaget's statement that child language development reflects the development of child cognition. Dyslexic children experience delays in cognitive development so that they have difficulty producing "dwitransitive" sentences that have more complex syntactic structures. Alternatively, they produce a "transitive" sentence that has a simpler syntactic structure with almost the same meaning.

Based on frequency of application, the existence of intransitive sentence (simple sentences and sentences derivation) in DC speech is high. From 270 complete sentence that collected, there are $106(=39.25 \%)$ intransitive sentence. Some examples can be seen in the data below.

(10) Bapakku kerja.

'My father works'

(11) Kodoknya melompat.

'The frog jumped'

In the data above it appears that the verbs that serve as predicates in the above sentences are mostly basic verbs. If this is attributed to the transitory level of a verb that the use of affixes can increase the degree of transitivity of the sentence, it can be stated that the number of basic verbs in the sentence spoken by DC can lead to high intransitive sentences in the DC speech.

Based on structure, the degree of simplicity sentence that its predicate filled by nonverba is equals with the sentence that has predicate filled by transitive verbs because it has common 
which it need an argument subject (this kind of sentence did not need an object).

Based on the pattern structure, the simple sentence that appears in the speech DC can be classified into five patterns of sequence categories, namely (1) a noun phrase + verbal phrase (NP+VP), (2) a noun phrase + noun phrase (NP1+NP2), (3) a noun phrase + phrases adjektival $(\mathrm{NP}+\mathrm{AP}),(4)$ a noun phrase + prepositional phrase $(\mathrm{NP}+\mathrm{PP})$, and (5) a noun phrase + phrases numeral $(\mathrm{NP}+\mathrm{NuP})$. Based on frequency of occurrence, all five basic sentence patterns can be sorted as in the following table.

TABLE I.

PATTERNS OF INDONESIA SIMPLE SENTENCE IN DYSLEXIC CHILDREN

\begin{tabular}{lllll}
\hline No & $\begin{array}{c}\text { Example of } \\
\text { sentences }\end{array}$ & $\begin{array}{c}\text { Pattern } \\
\text { Subj-Pred }\end{array}$ & Occurs & $\begin{array}{c}\text { Percentage } \\
(\%)\end{array}$ \\
\hline 1. & Aku pulang. & NP-VP & 66 & 38,82 \\
2. & Adikku laki-laki. & NP1-NP2 & 45 & 26,47 \\
3. & Nasinya panas. & NP-AP & 40 & 23,53 \\
4. & Ibu di rumah. & NP-PP & 10 & 5,88 \\
5. & Pensilku dua. & NP-NuP & 9 & 5,29 \\
\hline \multicolumn{5}{l}{ Total Number } \\
\hline
\end{tabular}

The table above shows that the simple sentence with NP+VP pattern has the highest frequency of occurrences. From 170 simple sentences in the speech of DC, there were 66 $(38,82 \%)$ simple sentences patterned NP+VP. For the next successive simple sentence patterned NP1+NP2 with 45 sentences $(26,47 \%), \mathrm{NP}+\mathrm{AP}$ there were 40 sentences $(23,53 \%)$, $\mathrm{NP}+\mathrm{PP}$ contained 10 sentences $(5,88 \%)$, and last $\mathrm{NP}+\mathrm{NuP}$ contained 9 sentences $(5.29 \%)$.

\section{2) Complex Sentence}

In addition to a simple sentence, the speech DC also found the complex sentence, the sentence have expanded beyond the limits of the phrase, so that its part is a combination of the two phrases, there is also each core phrase undergoing expansion so as to form new clause. There are two types of complex sentences that appear, which is equivalent complex sentence (coordinative) and subordinative complex sentence.

Here's some coordinative complex sentences data that appears in DC speech.

(12) Tidurnya jam 1, terus bangunnya jam 2.

'He sleep at 1 , then keep awake at 2'

(13) Opahku diracuni, tapi mental.

'My opah was poisoned but did not work'

(14) Hei, Dora ini baik, buaya itu jelek, nakal.

'Hey, Dora is good, the crocodile is ugly, naughty'

(15) Aku gak punya nenek, punyanya kakek.

'I do not have grandma, only grandpa'

(16) Aku bawa nasi, belum saya makan.
'I bring rice, i have not eaten'

Sentence (12) and (13) is a coordinative complex sentences because each sentence consists of two similar/ alignment clauses position. Sentence (12) structure is SUBJ-PRED, Conj SUBJ-PRED. Sentence (13) has a structure SUBJ-PRED, Conj PRED. Relating both clauses in the sentence (12) above is used conjunctions "terus" stating the relationship "continuous time", while for sentence (13) use conjunctions "tapi" stated "the opposite relationship". In this case occurs deletion of the SUBJ in the second clause because it is associated with the first SUBJ clause.

For sentence (14)--(16), it has an implicit between-clause relationship that means between-clause relationship not stated with conjunctions. Sentence (14) consists of three clauses with the functional structure of SUBJ-PRED, SUBJ-PRED, PRED. In the third clause, the SUBJ is exposed because it is aligned with the second SUBJ clause. Sentence (15) consists of two clauses with a functional structure SUBJ-PRED-OBJ, PREDOBJ. In the second clause, the SUBJ experiences a deletion because it is aligned with the first SUBJ clause. Sentence (16) consists of two clauses with a functional SUBJ-PRED-OBJ, PRED. In the second clause, the SUBJ aligned with the first OBJ clause is deleted. Although implicit, the between-clause relationship semantically stated the meaning of resistance, that is, the first clause expresses the opposite meaning of the second clause.

Here are some examples of subordinative complex sentences in a speech DC who has a relationship structure that is subordinate clauses.

(17) Orang yang pakai gelang itu bisa sakit kanker.

'People who wear that bracelet can get cancer'

(18) Kucingnya buru-buru sembunyi setelah anjingnya datang.

'Her cat hastily hid after her dog came'

(19) Fandani pulang karena kamu kelamaan.

'Fandani comes home because you are late'

(20) Bu guru ada di situ sampai aku gak kelihatan.

'The teacher is there until i'm invinsible'

(21) Bu guru marah, kelasnya kotor.

'The teacher is angry, her class is dirty'

Each sentence (17)--(21) above consists of two clauses with between-clause relationship is subordinate. For sentence (17)-(20) between-clause relationship is explicit, while for the sentence (21) between-clause relations coexist implicit. In sentence (17), the embedded clause, is "yang pakai gelang", is subordinate to the main clause SUBJ. Semantically, the embed clause expresses attribute relationships in the main clause. In sentence (18), the embedded clause, "anjingnya datang", semantically stated deadline time relationship to the main clause with conjunctions marked "setelah". In sentence (19), the embedded clause, which is "kamu kelamaan", semantically expressed causality for the main clause with conjunctions 
marked "karena". In sentence (20), the embedded clause, which "aku gak kelihatan", semantically the relationship due to its main clause with conjunctions marked "sampai". As for the sentence (21), the embedded clause, namely "kelasnya kotor", semantically remain clearly state a cause for the main clause despite its between-clause relationship without being marked by a conjunction.

Based on the data that has been collected and analyzed, it is known that the complete sentences produced by DC are very little. For overall data, it appears that the complex sentence in speech DC is not too much data found.

\section{Incomplete Sentence}

In addition to sentences that have a complete structure, in the speech DC found many incomplete sentences. The comparison of complete and incomplete sentences in DC speech is approximately 1:3. Incomplete sentences of course have a degree of simplicity more when compared with complete sentences. The core part that should be present in the sentence is often absorbed in the DC speech. The core parts that are experiencing the occurrence can be the function of Subject, Object, and even Predicate sentence. Therefore, incomplete sentences In general, the sentence that has been deleted can be traced from the context of the previous sentence.

\section{CONCLUSION}

In general, the sentences in the DC speech have a gradation of simplicity. The simplicity degrees based on the type of verbs in the predicate function and structure of the sentence (complete sentences and incomplete sentences). The fewer the number of arguments required by the core predicate verb of the sentence, the more simple the structure of the sentence is for DC. Simple sentences produced by DC can be sorted into two, namely simple sentences that predicate filled verbs and nonverbs. The "ekatransitive" sentence in the DC spell is quite high, 49 (=18.14\%) of the "ekatransitive" sentence. Another interesting point to consider in this section is that there are so many phenomena of using transitive verbs in the DC speech. Only, transitive verbs do not necessarily form a transitive sentence. This is because the transitive verb is not followed by the OBJ core argument that should be accompanying it. Sentences with predicate transitive verbs not accompanied by OBJ core arguments are grouped into intransitive sentences. "Dwitransitif" sentences are not found in DC speech. Dyslexic children experience delays in cognitive development so that they have difficulty producing "dwitransitive" sentences that have more complex syntactic structures. Alternatively, they produce a transitive sentence that has a simpler syntactic structure with almost the same meaning. The existence of intransitive sentences (simple sentences and derivation sentences) in the DC classified as high, $106(=39.25 \%)$ intransitive sentence.

Based on the structure, the degree of simplicity sentences filled by nonverba are equal with the sentence had predicate filled intransitive verbs because it has a similarity that requires one argument to be the subject (this type of sentence have no object). Based on the structure pattern, the simple sentences of DC can be classified into five categories. The simple sentence patterned NP+VP has the highest frequency of occurrences. From the 170 simple sentences that appear in the speech DC, there are $66(38.82 \%)$ simple sentences are patterned NP+VP. For the following sequential sentences NP1+N2 has 45 sentences $(26.47 \%)$, NP+AP contains 40 sentences $(23.53 \%)$, $\mathrm{NP}+\mathrm{PP}$ is 10 sentences $(5.88 \%)$, and the last $\mathrm{NP}+\mathrm{NuP}$ is 9 sentences $(5.29 \%)$. There are two types of complex sentences that appear, namely coordinative complex sentence and subordinative complex sentence. The complete sentence produced by DC is still very little. From the overall data it appears that the complex sentence in the DC speech is not too much data found. The comparison of complete and incomplete sentences in DC speech are approximately 1:3. Incomplete sentences of course have a degree of simplicity more when compared with complete sentences.

\section{REFERENCES}

[1] S. Shaywitz, "Dyslexia," N Engl J Med., vol. 338, pp. 307-312, 1998.

[2] Morkena and Froydis, "Reading in dyslexia across literacy development: A longitudinal study ofeffective connectivity," 2017. [Online]. $\quad$ Available: $\quad$ http://dx.doi.org/10.1016/ j.neuroimage.2016.09.060.

[3] S. Fisher and J. DeFries, "Developmental Dyslexia: Genetic Dissection of a Complex Cognitive Trait," Nat. Rev. 3, pp. 767-7781, 2002.

[4] "Definition of Dyslexia," 2002. [Online]. Available: https://dyslexiaida.org/definition-of-dyslexia/.

[5] R. Morris, S. Shaywitz, and B. Shaywitz, "The Education of Dyslexic Children from Childhood to Young Adulthood.," 2008. .

[6] M. Iglesias, "Alumnos con dislexia: Estrategias the educadores," 2002.

[7] Reggiani and Danilo, "Dyslexia and the Acquisition of Syntax Passive and Control," University Degli Study in Verona, 2012.

[8] M. Yilmas, "kelime tekrar tekniğinin akıcı becerilerini geliştirmeye etkisi Okuma," Türk Eğitim Derg. Bilim., vol. 6, no. 2, pp. 323-350, 2008.

[9] P. Somad, "Reading Guidance for Students berkesulitan Reading," Jassi My Son's J., vol. 1, pp. 38-51, 2002.

[10] B. Delphie, Education Children with Special Needs: In Settings Inclusive Education. Bandung. Bandung: PT Refika Aditama, 2006.

[11] B. Bryne, "Deficient syntactic control in poor readers: Is aweak phoneticmemory code responsible?," Appl. Psycholinguist., vol. 2, pp. 201-212, 1981.

[12] Muhadjir and Noeng, Research Methods Kualitati. Issue III. Yogyakarta: Rake Serasin, 2002.

[13] Dardjowidjojo and Sunjono, Echa 2000: The Story of Child Language Acquisition. Jakarta: Grasindo, 2000.

[14] Alwi and Hasan, Grammar Indonesian Baku, Third Edit. Jakarta: Balai Pustaka, 2010.

[15] N. Chomsky, The minimalist program. Cambridge: MIT Press, 1995. 